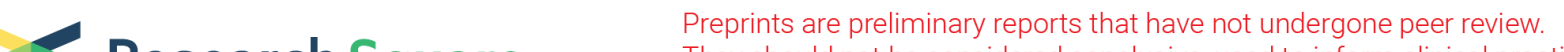 $\begin{array}{ll}\text { Research Square } & \text { They should not be considered conclusive, used to inform clinical practice, } \\ \text { or referenced by the media as validated information. }\end{array}$
}

\section{An Integrated Breathlessness Service Program in an Ambulatory Hospice Center- Sharing of Local Experience and Clinical Results}

Carmen Wai Lim Leung ( $\square$ Iwlc01@ha.org.hk)

Hong Kong Queen Elizabeth Hospital https://orcid.org/0000-0003-2964-9383

Kam Hung Wong

Department of Clinical Oncology, Queen Elizabeth Hospital

YL Irene Kwok

Department of Clinical Oncology, Queen Elizabeth Hospital

WM Leung

Department of Clinical Oncology, Queen Elizabeth Hospital

WC Chan

Department of Clinical Oncology, Queen Elizabeth Hospital

\section{Sally Wan}

Physiotherapy department, Queen Elizabeth Hospital

\section{Tiffany Tse}

occupational therapy department, Queen Elizabeth Hospital

\section{PS Yeung}

Occupational Therapy department, Queen Elizabeth Hospital

Harry Wong

Social Welfare Department, Queen Elizabeth Hospital

Joe Huang

Social Welfare Department, Queen Elizabeth Hospital

\section{Research article}

Keywords: Cancer, breathless, proactive education, therapeutic intervention, non-pharmacological, pharmacological

Posted Date: September 8th, 2020

DOI: https://doi.org/10.21203/rs.3.rs-31675/v1

License: (c) (1) This work is licensed under a Creative Commons Attribution 4.0 International License.

Read Full License 


\section{Abstract}

\section{Background:}

To improve patients' breathlessness and relieve their distress and anxiety.

\section{Methods:}

PROACTIVE group targets the lung cancer patients without significant breathlessness. These high-risk patients with their families will have proactive education on the measures for self-management on breathlessness so as to reduce its impact in due course. Patient's self- efficacy in mastering breathlessness are related to their predominant place of care at their last 6 months of life, their frequency of unplanned hospital admission and emergency unit attendance for the management of breathlessness.

THERAPEUTIC group recruits those cancer patients with significant breathlessness. The patient will have an Individual Comprehensive Breathlessness Assessment. Personalized pharmacological and nonpharmacological Interventions will be used. The care-givers will be empowered by providing relevant information and training up of their caring skills. Patient's self-rating symptom control, stress and confident scores were regularly monitored on every visit. The absolute changes of self-rating scores during their disease course were recorded.

\section{Results:}

Total 292 patients have been recruited (Proactive 227; Therapeutic 65) and retrospective analyzed. In the Proactive group, 76.5\% patients remained in community as their predominant place of care at their last 6 months of life. Their mean frequencies of unplanned hospital admission and emergency unit attendance per patient are 1.1 and 1.44, respectively (Corresponding local data were 2.5 and 3.4). In the Therapeutic group, $85 \%$ patients had moderate to high level breathlessness score at presentation which greatly affects their quality of life \{significant emotion stress (34\%) and unconfident feeling (50\%)\}. 78\% patients had 3 or less attendances due to their rapid clinical deterioration. The interventions are effective in improving or stabilizing both breathless patient's physical $(44 \% / 26 \%)$ and psychological status \{emotional stress (17\%/46\%) and confident score (24\%/28\%)\} despite their disease progressing.

\section{Conclusion:}

This Integrated Breathless Service Program is effective in improving both patients' physical and psychological status. Adopting a proactive approach can equip the high-risk patients and their care-givers with knowledge and skills for handling breathlessness when in need. Hence this facilitates timely intervention especially when cancer patients tend to deteriorate rapidly that sometimes the therapeutic interventions may not have time to practice.

\section{Background}


Breathlessness is a common and distressing symptom in many advanced cancers, causing much disability, anxiety, and social isolation (1-3). It is very frightening for patients and their families, and is often accompanied by feelings of loss of control over breathing leading to panic (4-6). Breathless patients report lower quality of life scores (7) and psychological and cognitive changes including anorexia, fatigue, poor concentration and decreased confidence (8). Furthermore, breathlessness imposes a large burden on the health care system associated with increased hospitalizations and prolonged lengths of stay due to inadequate symptom control. Breathlessness is also the fourth most common causes of palliative care patients visiting the emergency department (9).

There is a distinct clinical entity of "chronic breathlessness syndrome" which is defined as 'the experience of breathlessness that persists despite optimal treatment of the underlying pathophysiology and results in disability for the patient. The delineation of chronic breathlessness syndrome provides a focus for directed systematic clinical enquiry, including targeted intervention. Usual practice often stops at the point of optimized treatment of the underlying disease(s). However, there are non-pharmacological and pharmacological evidence-based interventions for chronic breathlessness as a therapeutic target which can improve quality of life for both patient and care-giver (10). Many studies on non-pharmacological interventions have been published including those showing that the hand-held fan (11-13); neuroelectrical muscle stimulation, chest wall vibration and breathing training (14) can be helpful in reducing the sensation of breathlessness.

The experience of breathlessness 'derives from interactions among multiple physical, psychological, social and spiritual factors, and may induce secondary physiological and behavioral responses.' (15) Hence treating breathlessness is challenging and requires a multi-disciplinary approach combining both non-pharmacological and pharmacological interventions in order to provide effective treatment. Maddocks et al have reported that holistic breathlessness services are highly valued by recipients and can lead to significant improvements in the distress caused by breathlessness and depression. Outcomes of improved mastery and reduced distress caused by breathlessness are not influenced by patient diagnosis, lung function or health status. Stakeholders highlighted the need for improved access to person-centered, multi-professional breathlessness services and support for informal care-givers. (16).

It is also clear that family care-givers of breathless patients carry substantial physical burdens and suffer severe anxiety, distress, feelings of helplessness and isolation in their own right (17). Hence, effective support to lessen care-givers' stress has a pivotal role in the optimal management of this difficult symptom. Successful management of this multi-dimensional symptom requires a multidisciplinary approach and support of the family unit to be most effective.

\section{Setting:}

A new Integrated Breathlessness Service Program (IBSP) was started since March 2014 in the Ambulatory Hospice Center under Department of Clinical Oncology of Queen Elizabeth Hospital of Hong Kong. The objectives of this day care IBSP were firstly to improve cancer patients' symptoms of breathlessness and their quality of life and secondly to relieve the distress and anxiety of patients and 
their families. This paper presents data on the effectiveness of this IBSP in the Ambulatory Hospice Centre.

\section{Methods}

This is a retrospective review of 292 consecutive patients enrolled to the IBSP in the Ambulatory Hospice Centre from March 2014 to October 2018. All the electronic medical records under public health care system in the territories and printed medical charts of the department were reviewed. Almost all the clinical progress of the recruited patients' can be reviewed since majority of terminal patients were taking care under the public health care system in Hong Kong.

Palliative cancer outpatients with a palliative performance scale $>/=60 \%$ (table 1 ) were the main target for the team. The day service program provided a single point of access for patients and their families to the multidisciplinary team. At each visit patients and families were jointly assessed by the palliative care clinician, palliative care nurse, therapist (physio and occupational therapist in alternate sessions) and social worker.

Table 1:

Table 1:

Palliative Performance Scale (PPSv2) version 2

\begin{tabular}{|c|c|c|c|c|c|}
\hline $\begin{array}{l}\text { Pps } \\
\text { Level }\end{array}$ & Ambulation & $\begin{array}{l}\text { Activity } 8 \text { Evidence of } \\
\text { Disease }\end{array}$ & Sell-Care & Intake & Consclious Lovel \\
\hline 1005 & Fuil & $\begin{array}{l}\text { Normal activily s work } \\
\text { No evidence of disease }\end{array}$ & Fut & Normaly & Funt \\
\hline$\Phi \pi$ & Fut & $\begin{array}{l}\text { Normal activity } \delta \text { work } \\
\text { Some evidence of disease }\end{array}$ & Fut & Normal & Fut \\
\hline 805 & Fut & $\begin{array}{l}\text { Normal activity with Etlort } \\
\text { Some evidence of disease }\end{array}$ & Fuit & $\begin{array}{l}\text { Normal or } \\
\text { reduced }\end{array}$ & Full \\
\hline 705 & Reduced & $\begin{array}{l}\text { Unabie Normal Job Work } \\
\text { Signifcart disease }\end{array}$ & Fut & $\begin{array}{l}\text { Normal of } \\
\text { reduced }\end{array}$ & Fut \\
\hline 605 & Reduced & $\begin{array}{l}\text { Unabie hobby house work } \\
\text { Sipnifcart disease }\end{array}$ & $\begin{array}{c}\text { Occasioner assistance } \\
\text { necessery }\end{array}$ & $\begin{array}{l}\text { Normal of } \\
\text { feduced }\end{array}$ & $\begin{array}{l}\text { Fult } \\
\text { or Contusion }\end{array}$ \\
\hline $50 \%$ & Mainly \$ncle & $\begin{array}{l}\text { Unable to do any work } \\
\text { Extensive disease }\end{array}$ & $\begin{array}{c}\text { Considerable assistance } \\
\text { tegured }\end{array}$ & $\begin{array}{l}\text { Normal of } \\
\text { reduced }\end{array}$ & $\begin{array}{l}\text { Full } \\
\text { os Contusion }\end{array}$ \\
\hline $40 \%$ & Mainly in Bed & $\begin{array}{l}\text { Unable to do most activity } \\
\text { Extensive disease }\end{array}$ & Mainly assistance & $\begin{array}{l}\text { Normal or } \\
\text { reduced }\end{array}$ & $\begin{array}{l}\text { Fut or Drowsy } \\
+ \text { +f Contusion }\end{array}$ \\
\hline 305 & $\begin{array}{l}\text { Totaly Bed } \\
\text { Bound }\end{array}$ & $\begin{array}{l}\text { Unable so do any actovity } \\
\text { Extensive disease. }\end{array}$ & Total Care & $\begin{array}{l}\text { Normal of } \\
\text { reduced }\end{array}$ & $\begin{array}{l}\text { Fut or Drowsy } \\
+ \text { Contusion }\end{array}$ \\
\hline 205 & $\begin{array}{l}\text { Totally Bed } \\
\text { Bound }\end{array}$ & $\begin{array}{l}\text { Unable to do any actovity } \\
\text { Extensive cisease }\end{array}$ & Total Cave & $\begin{array}{c}\text { Minimal to } \\
\text { sips }\end{array}$ & $\begin{array}{l}\text { Ful or Drowsy } \\
* \text { Contusion }\end{array}$ \\
\hline $10 \%$ & $\begin{array}{c}\text { Totally Bed } \\
\text { Bosing }\end{array}$ & $\begin{array}{l}\text { Unable to do any actovity } \\
\text { Extensive disease }\end{array}$ & Total Care & $\begin{array}{l}\text { Mouth care } \\
\text { only }\end{array}$ & $\begin{array}{c}\text { Drowsy or Coma } \\
\text { +f Contusion }\end{array}$ \\
\hline os & Dewh & - & - & - & - \\
\hline
\end{tabular}

The day service program was divided into two streams:

1. The 'proactive group' $(P G)$ recruited lung cancer patients newly referred to our Ambulatory Hospice Center. These patients have a high risk of developing chronic breathlessness syndrome during their disease course. The intervention of the program focused on educating patients proactively on evidence-based measures to help them self-manage breathlessness and reduce its impact if needed in their disease course. 
Firstly, all patients and their family members attended an orientation talk conducted by the multidisciplinary team at their first attendance at the center. This session included (i) with general information about the program (ii) education/counselling on strategies to self-manage breathlessness.

Secondly, each patient then had an individual comprehensive breathlessness assessment (ICBA), which encompassed both qualitative and quantitative bio-psycho-physical aspects of this complex symptom. This assessment included a detailed history, quantitative assessment of the impact of the symptom and quality of life.

1. Physical aspect (Modified BORG Dyspnea Scores (Figure 1), physiological parameters (Figure 2) and co-related VAS pain scores)

Modified BORG Dyspnea Scale was used for assigning verbal descriptors to numerical values between zero and ten. It is a popular tool to assess the intensity of dyspnea in the research literature.

Figure 1 Modified BORG dyspnea score

This scale consists of both verbal (10) and numerical (12) descriptions for dyspnea assessment. Patients are asked to tick the boxes that reflect their dyspnea perception best.

\begin{tabular}{|c|c|c|c|}
\hline Scores & Shortness of breath & At rest & During activity \\
\hline 0 & Nothing at all & & \\
\hline 0.5 & Very very slight & & \\
\hline 1 & Very slight & & \\
\hline 2 & Slight & & \\
\hline 3 & Moderate & & \\
\hline 4 & Somewhat severe & & \\
\hline 5 & severe & & \\
\hline \multicolumn{4}{|l|}{6} \\
\hline 7 & Very severe & & \\
\hline \multicolumn{4}{|l|}{8} \\
\hline 9 & Very very severe & & \\
\hline 10 & Maximal & & \\
\hline
\end{tabular}

1. Emotional aspect \{stress score, General Anxiety Disorder-7 (GAD-7), Patient health questionnaire (PHQ-9)\}, 
The distress caused by a symptom arises not only from the symptom's intensity, but also from other factors such as the degree of impairment it imposes, and meaning of that symptom for that individual (influenced by many factors including personality, past experiences and coping styles). These are often referred to as the sensory and affective aspects of a symptom. The program assesses these with validated scales on emotional disturbance (Fig 3), depression (PHQ-9) and anxiety scores (GAD-7) that permit an assessment of distress caused by breathlessness (18). However, some palliative care patients are old and/or too distressed to these assessment tools.

\section{Confidence (stress score) and social aspects}

Their psychosocial status was also regularly monitored by our social worker and extra sessions of counselling would be arranged if needed.

The flowchart of the patients in this PG is revealed in Figure 5. Patients who present significant breathlessness \{Modified BORG dyspnea score $\geqq$ slight $(2 / 10)$ at rest and/or $\geqq$ moderate $(3 / 10)$ during activities\} were discharged from the PG and transferred directly to the Therapeutic group (TG) of this program. The remaining patients, after completing the proactive program, were followed up in the general palliative care clinic at 4-8-week intervals. If patients later developed significant breathlessness as their disease progressed, they would also be referred to the TG for further intensive interventions.

The primary aim of the PG was to assess the efficacy of the proactive education on skills and knowledge of high-risk patients and their families in handling breathlessness and related symptoms. After appropriate proactive training, patient's self- efficacy in mastering breathlessness in the later course of disease journey seems to be related to

1. The predominant place of care at their last 6 months of life.

Community-based care as defined by their length of stay in hospital was less than 2 months and institution-based care as defined by their length of hospital stay more than 2 months before death.

\section{Frequency of unplanned hospital admission and Accident and Emergency attendance for the} management of chest symptoms during their later disease course.

These two parameters are used as outcome measurements in this paper to assess the efficacy of intervention in the PG cohort.

1. The 'therapeutic group'(TG) enrolled all cancer patients under the care of the center with active significant breathlessness. This service (one session per month) focused on therapeutic interventions to palliate breathlessness.

Firstly, the patient had an ICBA done by the multidisciplinary team. Secondly, the patient was offered personalized interventions for their breathlessness based on the results of the assessment including 
breathlessness severity, the underlying pathophysiological mechanisms and the psychosocial impact. The interventions could include both pharmacological and non-pharmacological approaches. (Table 2)

Table 2

Target Intervention

Patient Pharmacological treatment:

Opioid, bronchodilator, steroid and benzodiazepine (Drug education by a palliative care nurse with information pamphlets and subsequent phone follow-up for compliance and drug effect)

\section{Non-pharmacological treatment:}

1. Breathing control training e.g. pursed lip breathing

2. Energy conservation techniques e.g. activity pacing and graded exercise, relaxation exercises and positioning

3. Coughing exercise

4. Postural drainage

5. Hand-held fan therapy

6. Oxygen therapy

7. Walking aid assessment and prescription

8. Special referral to other team members (e.g. clinical psychologist or dietitian) if needed

Care-

givers

1. Empowerment of care-givers by providing relevant information, and enhancement of their knowledge of caring for breathlessness and promoting the care-givers' self-care.

2. Home visit by occupational therapists for education on the activities of daily living and home modification to cater individual needs.

Patients will be followed up and monitored jointly by the multidisciplinary team for the treatment effectiveness as this will vary between patients, and other interventions may be trialed on an individual basis steps by steps. The physiotherapists or occupational therapists also offer individual counselling to patients and their care-givers on every visit. The progress of their home- based chest rehabilitation will be assessed. Patients' psychosocial status is also regularly monitored by the social worker and extra sessions of counselling had been arranged in case if needed.

The flowchart of the patients in the TG is set out in Figure 5. When the patients' symptom of breathlessness had been improved (modified BORG dyspnea score reduced by 2 points) and they were confident in self-management of the symptom, patients were discharged back to the general palliative care clinic for follow-up.

The primary aim of the therapeutic group intervention was to enhance patients' capability to handle their current breathlessness symptoms by assessing their change in self-rating physical modified BORG dyspnea, emotional and confidence scores on every day service visit during the course of therapeutic interventions. The absolute change is measured from the maximum improvement or deterioration of 
score during their disease course. These changes in self-rating parameters are reported in this paper as the outcome measurement to assess the efficacy of the interventions in the TG.

\section{Results}

A total number of 292 patients were recruited (PG 227 patients; TG 65 patients) consecutively to the IBSP between March 2014 and October 2018. The details of the case allocation are shown in Figure 6.

\section{For the Proactive Group (PG) - lung cancer patients (high risk of developing chronic breathless syndrome):}

After exclusion of eighteen patients who were triaged directly to the TG, there were 209 patients in total in the PG. The mean age was 72.6 years old (range 38 to 95 years old). 131 of them were male (58\%). The majority of the patients had palliative performance score $>/=60$ at recruitment. The participation of caregivers is central to the program: the mean number of relatives participated per family was 1.17.

- Patients' baseline characteristics

The baseline self-rating physical, emotional stress and confidence scores of these 209 PG participants are summarized on table 3 .

Table 3: Patient's baseline characteristic of the PG, on a scale of $0-10$, with 0 is no at all and 10 is the worst

\begin{tabular}{|lllllll|}
\hline Self-rating scores (0-10) & $0-0.5$ & $1-2$ & $3-4$ & $5-6$ & $7-8$ & $9-10$ \\
\hline BORG dyspnea at rest (\%) & $\mathbf{6 5}$ & $\mathbf{2 9}$ & 5 & 0 & 1 & 0 \\
\hline BORG dyspnea during activities (\%) & $\mathbf{2 7}$ & $\mathbf{3 8}$ & 27 & 5 & 2 & 1 \\
\hline Emotion disturbance (\%) & 53 & 16 & 14 & $\mathbf{8}$ & $\mathbf{7}$ & $\mathbf{0 . 6}$ \\
\hline Unconfident feelings (\%) & 36 & 19 & 21 & $\mathbf{1 7}$ & $\mathbf{4}$ & $\mathbf{3}$ \\
\hline
\end{tabular}

Forty-one patients are too old to comprehend the BORG rating system and were not included. Among the rest, $158(94 \%)$ and $108(65 \%)$ patients experienced less than slight $(>/=2)$ breathlessness symptom at rest and during activity. 25 (16\%) out of 156 assessable patients and $36(24 \%)$ out of 154 patients had significant emotional stress score and unconfident score (score of more than 5 on a scale of $0-10$ ) respectively.

(II) Outcome of the cohorts

Among the cohort of $\mathrm{PG}, 135$ patients (64.6\%) had breathlessness symptom throughout their disease course since the recruitment, 27 patients (12.9\%) developed breathlessness in the later part of their disease journey and 47 patients $(22.4 \%)$ did not present with any breathlessness symptom all along (Fig 
7). Since the objective of this program was to study the efficacy of proactive education and training to handle the breathlessness symptom, those patients did not experience any breathlessness was excluded from analysis. In addition, a total of 17 patients with rapidly deteriorating symptom control were subsequently referred to the TG for more intensive non-pharmacological interventions. However, only six patients attended the intervention service and the rest died shortly while waiting for the monthly therapeutic intervention session.

- Primary endpoint measurements

1. Use of pharmacological interventions in their disease course

A total of 162 patients in the PG were symptomatic i.e. either presented with dyspnea throughout or developed dyspnea later in their disease course. 77 patients (48\%) required regular pharmacological interventions (Table 4). At least half of the patients could use non-pharmacological interventions alone to control their symptom.

Table 4

\begin{tabular}{|ll|}
\hline Pharmacological interventions & Incidence \\
\hline Morphine & $58 \%$ \\
\hline Bronchodilator & $49.3 \%$ \\
\hline Home Oxygen therapy & $24 \%$ \\
\hline Benzodiazepine & $35 \%$ \\
\hline
\end{tabular}

\section{Survival rate}

The median survival for the symptomatic proactive group is 21 weeks (range 0.14 to 169) and their 1-year survival is $22 \%$. At the time of analysis, 149 patients (92\%) already died of disease and one patient lost to follow up. Twelve patients were still actively followed up in the program at the time of analysis.

1. Predominant place of care in last six months of life for the symptomatic proactive group In this cohort, 124 patients (76.5\%) remained in community-based care and only 25 patients (16.7\%) needed institution-based care in their last six months of life.

1. Frequency of unplanned hospital admission and Accident and Emergency attendance

Based on the patients' electronic records in Hong Kong's public healthcare system, the patients' frequencies of emergency department attendances and unplanned hospital admissions after enrolling into the program were recorded (Fig 8). This study demonstrated that the majority of admissions were through emergency department rather than hospice clinic ( $76 \%$ vs $24 \%$ ). About half of the patients ( $48 \%$ ) on the PG attended emergency department and admitted to hospital only once in their disease course and 
usually at their terminal phase. The majority of proactive group patients (89\%) attended emergency department fewer than 2 times during their disease journey after receiving interventions from our proactive breathlessness day program. $19 \%$ of the patients did not need emergency medical care at all. Overall, the mean unplanned admission and emergency department attendance per patient are 1.1 and 1.44 , respectively.

\section{For the Therapeutic group- patients with active significant breathlessness:}

A total of 65 patients were recruited consecutively into the TG. The mean age was 72.45 years old (range 51 to 93 years old). 39 of them were male $(60 \%)$. Most patients had lung cancer $(70 \%)$ followed by colon cancer $(8 \%)$ and breast cancer $(5 \%)$ and others $(17 \%)$. The majority of the patients had a palliative performance score $>/=60$ at recruitment.

- Patient's baseline characteristics and duration of services

A significant number of the patients (85\%) had moderate to high level exertion breathless score at presentation (BORG dyspnea score $>/=3$ during activity). This greatly affected their quality of life as shown by their high incidence of significant emotion stress (34\%) and unconfident feeling (50\%) i.e. severity score of more than 5 on a scale of $0-10$. (Table 5 )

\begin{tabular}{|lllllll|}
\hline Self-rating scores (0-10) & $0-0.5$ & $1-2$ & $3-4$ & $5-6$ & $7-8$ & $9-10$ \\
\hline BORG dyspnea at rest (\%) & 31 & 51 & $\mathbf{1 6}$ & $\mathbf{0}$ & $\mathbf{2}$ & $\mathbf{0}$ \\
\hline BORG dyspnea during activities (\%) & 2 & 13 & $\mathbf{5 8}$ & $\mathbf{1 9}$ & $\mathbf{6}$ & $\mathbf{2}$ \\
\hline Emotion disturbance (\%) & 43 & 10 & 14 & $\mathbf{2 3}$ & $\mathbf{1 0}$ & $\mathbf{0}$ \\
\hline Unconfident feelings (\%) & 23 & 11 & 17 & $\mathbf{3 6}$ & $\mathbf{1 1}$ & $\mathbf{2}$ \\
\hline
\end{tabular}

Table 5: Patient's baseline characteristics of the Therapeutic group, on a scale of 0-10, with 0 is no at all and 10 is the worst

The majority of the patients had only received a short period of service (78\% patients had 3 or fewer monthly attendances) due to their rapid clinical deterioration which ended up with hospitalization and/or death (Fig 9).

- Effectiveness of the Therapeutic Interventions

All patients required regular intensive pharmacological interventions and non-pharmacological interventions to control their symptom. The results of 46 patients were analyzed for their maximum absolute changes in BORG, emotional stress and unconfident scores. The other nineteen patients were excluded from analysis since they were not available for further assessment in our monthly program after the first attendance. The reasons are namely death shortly after joining the program (37\%), 
hospitalization (37\%), referring out for other symptoms control e.g. pain (5\%), refusal to attend (5\%) and others $(16 \%)$.

The results suggest that the therapeutic intervention program is effective in improving breathless patient's physical status. Twenty patients (44\%) and 22 patients (48\%) experienced improvement of dyspnea symptom at rest and during activity, respectively. The median score of changes were 2 (range 0.5 to 5 out of 10 ) at rest and 1.5 (range $1-5$ out of 10 ) during activity. Furthermore, twelve patients (26\%) reported stable dyspnea during activity throughout their disease course despite their disease progressing.

For the psychological status, more patients experienced improvement or stable in their emotional stress score (17\% / 46\%) and unconfident score (24\% / 28\%). The median score of improvement for emotional stress score and unconfident score were 3.5 (range 2-6) and 4 (range 1 to 7), respectively (Fig 10).

Emotion stress and confidence scores (46 patients)

The absolute change is measured from the maximum improvement

or deterioration of score during their whole disease journey

\begin{tabular}{|lllll|}
\hline & $\begin{array}{l}\text { No } \\
\text { change }\end{array}$ & Improve & Deteriorate & $\begin{array}{l}\text { Cannot comprehend the } \\
\text { test }\end{array}$ \\
\hline $\begin{array}{l}\text { Emotional Stress } \\
\text { core }\end{array}$ & $46 \%$ & $\begin{array}{l}17 \% \\
* 3.5(\text { range } 2-\end{array}$ & $\begin{array}{l}\text { *3.5 (range 1- } \\
7 \text { ) }\end{array}$ & \\
\hline Confidence scores & $28 \%$ & $24 \%$ & $26 \%$ & $22 \%$ \\
& & $* 4$ (range 1-7) & $* 3$ (range 1-6) & \\
\hline
\end{tabular}

* Median score of change

For the outcomes of the patients in the TG, only fifteen patients (22\%) could be discharged from the program due to stable or improved condition. A significant number of patients dropped out from the program due to deterioration resulting in hospitalization (32\%) or death $(28 \%)$. The details are summarized in Fig 11.

\section{Discussion}

The results of the evaluation of the Proactive education and Therapeutic intervention groups in the IBSP suggest that the impact of the symptom and the quality of life of the patients and their care-givers can be improved by the multi-disciplinary and personalized approach.

It is well-known that lung cancer patients have a high risk of developing breathlessness in their disease course. In the PG cohorts, the dyspnea incidence is up to $77 \%$. In addition, this group of patients tends to 
deteriorate rapidly and they may not have enough time for the interventions to put into practice. Hence, it is postulated that a proactive approach can equip the high-risk patients or their care-givers with knowledge and skills for handling breathlessness symptom.

Since this is a retrospective review, the efficacy of proactive approach to equip them with basic skills cannot be directly measured. However, it can be reflected in their later frequency of emergency department attendance, unplanned admission for the management of chest symptoms and more importantly their capacity of staying in community- based care in their last six months of life. In the cohort of these high-risk lung cancer patients, the majority of them $(76.5 \%)$ could continue caring at home till the very end of their life. Hence the efficacy of this proactive approach is very valuable to patients and satisfies their wishes of caring at home and staying with their families.

Empowering them by the non-pharmacological interventions was shown to decrease their frequency of emergency department attendance and unplanned admission. Overall, for the PG lung cancer patients, the mean admission and mean emergency attendance per patient are 1.44 and 1.1 respectively. There is a significant reduction as compared to our local data as recorded that the mean number of admission and emergency attendance of cancer patients to all public hospitals in the last 6 months of life are 3.4 and 2.5 respectively (19).

Furthermore, the compliance of family members' participation was also satisfactory. The mean number of relatives participated per family is 1.17. All patients and their families were receiving group education. The interactive group dynamics during which can facilitate free communication to discuss their experience including emotional disturbance e.g. anxiety and fear, and to acknowledge the impact of breathlessness in their lives. Care-giver empowerment has a pivotal role in the management of patients' dyspnea symptom in community.

In the TG cohort, our interventions were developed from the Cambridge BIS Manual. But our targets are especially for cancer patients. There are high number of patient $(72 \%)$ had moderate to high level exertion dyspnea score at presentation. This greatly affects their quality of life as evidenced by significant percentage of the patients with substantial emotional disturbance and unconfident feelings. Advanced cancer patients tend to have more distress than non-cancer patients. Hence in the program, we had laid special focus on both non-pharmacological and pharmacological interventions to all the recruited patients. An individualized and multidisciplinary approach is taken to manage this complex symptom. Patients and the families can have a single of access to our multidisciplinary team in the ambulatory hospice center to have their condition regularly monitored and their intervention plan was adjusted accordingly.

Despite the fact that the therapeutic interventions program was well accepted by the participants and their family, there was a high rapid dropout rate and low level of attendance as recorded in the program. Fast deterioration of their clinical condition was observed. In addition, due to the monthly joint clinic time slot limitation, these group of patients with significant breathlessness on average only received less than three sessions of services over their 2-3 months life span. In view of the short life expectancy of these 
significant breathless patients, increase the frequency of therapeutic interventions joint clinic to weekly or biweekly might help. Timely interventions can palliate their symptoms more effectively and decrease the unnecessary emergency medical attendance and admission.

However, despite of the short interval of intervention service, this IBSP is effective in improving both breathless patient's physical (total $70 \%$; $48 \%$ improve and $22 \%$ no change) and psychological status (total $63 \% ; 17 \%$ improve and $46 \%$ no change). As the symptom likely will aggravate with disease progression, no deterioration in physical and psychological should also be regarded as a benefit to patients. Similarly, up to $52 \%$ of the patients got no deterioration in confidence despite the disease continuously progressed. Hence, helping patients to gain control over breathlessness is utmost important. Though the breathlessness cannot be cured but the interventions can significantly decrease their stress related to this frightening symptom and it is helpful to shorten their recovery time in episodes of breathlessness. As a result, significant number of the patients was more confident for self-management. Overall, our local results were comparable to that reported in international standards $(4,20)$. This suggests the Breathless Intervention Service Model was effective in both western and eastern world with different culture and living environment.

\section{Conclusion}

Over the last four years, a total number of 292 patients have been recruited to this Integrated Breathlessness Service Program. The results of the program are encouraging. Overall, the results of the evaluation suggest that our programs help patients and their families achieve an increased sense of selfcontrol, reduced sense of breathlessness and associated anxiety. The program was well accepted by the participants and their families. Dedicated multidisciplinary team together with customized pharmacologic management and non-pharmacologic management approach given in a coordinated manner is the key to improve the outcomes of dyspnea management. This Integrated Breathlessness Service Program is effective in improving both breathless patients' physical and psychological status. Adopting a proactive approach can equip the high-risk patients or their care-givers with knowledge and skills for handling breathlessness symptom when in need. Hence this facilitates timely intervention especially when cancer patients tend to deteriorate rapidly that sometimes the therapeutic interventions may not have time to practice. Care-giver empowerment has a pivotal role in the management of patients' dyspnea symptom in community. This program can effectively decrease the burden imposing on the health care system as evidenced by significant decrease in the mean number of admission and emergency attendance of cancer patients to public hospitals.

\section{Abbreviations}

1. Integrated Breathlessness Service Program (IBSP)

2. Proactive group (PG)

3. Individual comprehensive breathlessness assessment (ICBA) 
4. Visual Analog Scale (VAS)

5. General Anxiety Disorder-7 (GAD-7)

6. Patient health questionnaire (PHQ-9)

7. Therapeutic group (TG)

\section{Declarations}

Ethics approval and consent to participate:

- The study was reviewed and approved ( Ref KC/KE-20-0160/ER-3) by the Research Ethics Committee under Hospital Authority of Hong Kong in accordance with the ethical standards of the 1964 Declaration of Helsinki and its later amendments. The need for consent was deemed unnecessary according to local regulations for retrospective studies.

Consent for publication

- Not applicable.

Availability of data and material

- Data and material of this study will be made available on the public electronic records and departmental patient charts

Competing interests

- The authors declare that they have no competing interests.

Funding:

- not applicable

Authors' information

Affiliations

- Clinical oncologist and consultant of palliative care at the Department of Clinical Oncology, Queen Elizabeth Hospital, Hong Kong

- Dr Carmen Wai Lim Leung (CL)

- Dr Wong Kam Hung (KHW)

- Dr Irene YL Kwok (IK)

- Advanced Practice Nurse; Palliative Care Team of Li-Ka Shing Hospice Day Center under Clinical Oncology Department of Queen Elizabeth Hospital, Hong Kong

$\circ$ WC Chan (WC) 
- WM Leung (WM)

- Physiotherapist; Palliative Care Team of Li-Ka Shing Hospice Day Center under Clinical Oncology Department of Queen Elizabeth Hospital, Hong Kong

- Sally Wan (SW)

- Occupational therapists; Palliative Care Team of Li-Ka Shing Hospice Day Center under Clinical Oncology Department of Queen Elizabeth Hospital, Hong Kong

- Tiffany Tse (TT)

- PS Yeung (PS)

- Social worker; Palliative Care Team of Li-Ka Shing Hospice Day Center under Clinical Oncology Department of Queen Elizabeth Hospital, Hong Kong

- Harry Wong (HW)

$\circ$ Joe Huang $(\mathrm{JH})$

Authors' contributions:

- $\mathrm{CL}$ and KHW designed the study, analyzed the data, performed all statistical analyses and wrote the manuscript. IK, WC, WM, SW, TT, PS, TT, PS designed the study and supervised data collection. All authors read and approved the final manuscript.

\section{Acknowledgments:}

1. Palliative care team of Li-Ka Shing hospice day center under Clinical Oncology Department of Queen Elizabeth Hospital

2. Dr Sara Booth, Honorary Senior Lecturer at King's College London.

\section{References}

1. Currow DC, Abernethy AP, Ko DN. The active identification and management of chronic refractory breathlessness is a human right, Thorax 2014: 69: 393-94

2. MH Gysels, IJ Higginson. The lived experience of breathlessness and its implications for care: a qualitative comparison in cancer, COPD, heart failure and MND. BMC Palliat Care, 10 (2011), p. 15

3. MB Parshall, RM Schwartzstein, L Adams, et al. An official American Thoracic Society statement: update on the mechanisms, assessment, and management of dyspnea. Am J Respir Crit Care Med, 185 (2012), pp. 435-452

4. Higginson IJ, Claudia Bausewein. An integrated palliative and respiratory care service for patients with advanced disease and refractory breathlessness: a randomised controlled trial. Lancet respiratory medicine: 2014 Dec;2(12):979-87 
5. H Seow, L Barbera, R Sutradhar, et al. Trajectory of performance status and symptom scores for patients with cancer during the last six months of life.J Clin Oncol, 29 (2011), pp. 1151-1158

6. L Barbera, C Taylor, D Dudgeon. Why do patients with cancer visit the emergency department near the end of life? CMAJ, 182 (2010), pp. 563-568

7. Smith EL, Hann DM, Ahles TA, et al. Dyspnea, anxiety, body consciousness, and quality of life in patients with lung cancer. J Pain Symptom Manage. 2001 Apr;21(4):323-9

8. Bernhard J, Ganz PA. Psychosocial issues in lung cancer patients (Part 2). Chest 1991 Feb;99(2):4805.

9. National Hospital Ambulatory Medical Care Survey: 2010 emergency department summary tables. 2010. http://www.cdc.gov-/nchs/data/ahcd/nhamcs_emergency/2010_ed_web_tables.pdf (Last accessed in Aug 2014).

10. Miriam J. Johnson, Janelle Yorke, et al, Towards an expert consensus to delineate a clinical syndrome of chronic breathlessness, European Respiratory Journal 2017 49: 1602277

11. Bausewein C, Booth S, Gysels M, Kühnbach R, Higginson IJ. Effectiveness of a hand-held fan for breathlessness: a randomised phase II trial. BMC Palliat Care. 2010; 9:22. Published 2010 Oct 19.

12. Tim Luckett, Jane Phillips et al, Contributions of a hand-held fan to self-management of chronic breathlessness; European Respiratory Journal 2017 50: 1700262;

13. Tracy Smith, Jin-Gun Cho et al, Hand held fans for dyspnea relief in COPD: Physical properties and patient perceptions; European Respiratory Journal 2016 48: PA719;

14. Mark B. Parshall, Richard M. Schwartzstein, et al, An Official American Thoracic Society Statement: Update on the Mechanisms, Assessment, and Management of Dyspnea; Am J Respir Crit Care Med. 2012;185(4):435-452.

15. Matthew Maddocks, Lisa Jane Brighton, Sara Booth, et al, Holistic services for people with advanced disease and chronic or refractory breathlessness: a mixed-methods evidence synthesis; HEALTH SERVICES AND DELIVERY RESEARCH 2019 VOL. 7 NO. 22

16. Bausewein C, Booth S, Gysels M, Higginson I. Non-pharmacological interventions for breathlessness in advanced stages of malignant and non-malignant diseases. Cochrane Database Syst Rev. 2008 Apr 16;(2):CD005623.

17. Sara Booth, Catherine Moffat. Et al. Building a Breathlessness Intervention Service. The Cambridge BIS Treatment Manual. Support for carers. pp 7

18. Smith EM, Gomm SA, Dickens CM. Assessing the independent contribution to quality of life from anxiety and depression in patients with advanced cancer. Palliat Med. 2003 Sep;17(6):509-13

19. Drs TC Lam, KK Yuen. Territory-wide Review of Palliative Care Service for Hong Kong Cancer Patients 2006-2015: Implications for Future Service Development. Conference presentation in Annual Scientific Meeting, the Hong Kong College of Radiologists on $18^{\text {th }}$ Nov, 2018

20. Sara Booth, Catherine Moffat, et al, Developing a Breathlessness Intervention Service for Patients with Palliative and Supportive Care Needs, Irrespective of diagnosis, Journal of Palliative Care 
$27: 1 / 2011 ; 28-36$

Figures

\begin{tabular}{|c|c|c|c|}
\hline Scores & Shortness of breath & At rest & During activity \\
\hline 0 & Nothing at all & & \\
\hline 0.5 & Very very slight & & \\
\hline 1 & Very slight & & \\
\hline 2 & Slight & & \\
\hline 3 & Moderate & & \\
\hline 4 & Somewhat severe & & \\
\hline 5 & severe & & \\
\hline 6 & & & \\
\hline 7 & Very severe & & \\
\hline 8 & & & \\
\hline 9 & Very very severe & & \\
\hline 10 & Maximal & & \\
\hline
\end{tabular}

Figure 1

Modified BORG dyspnea score 


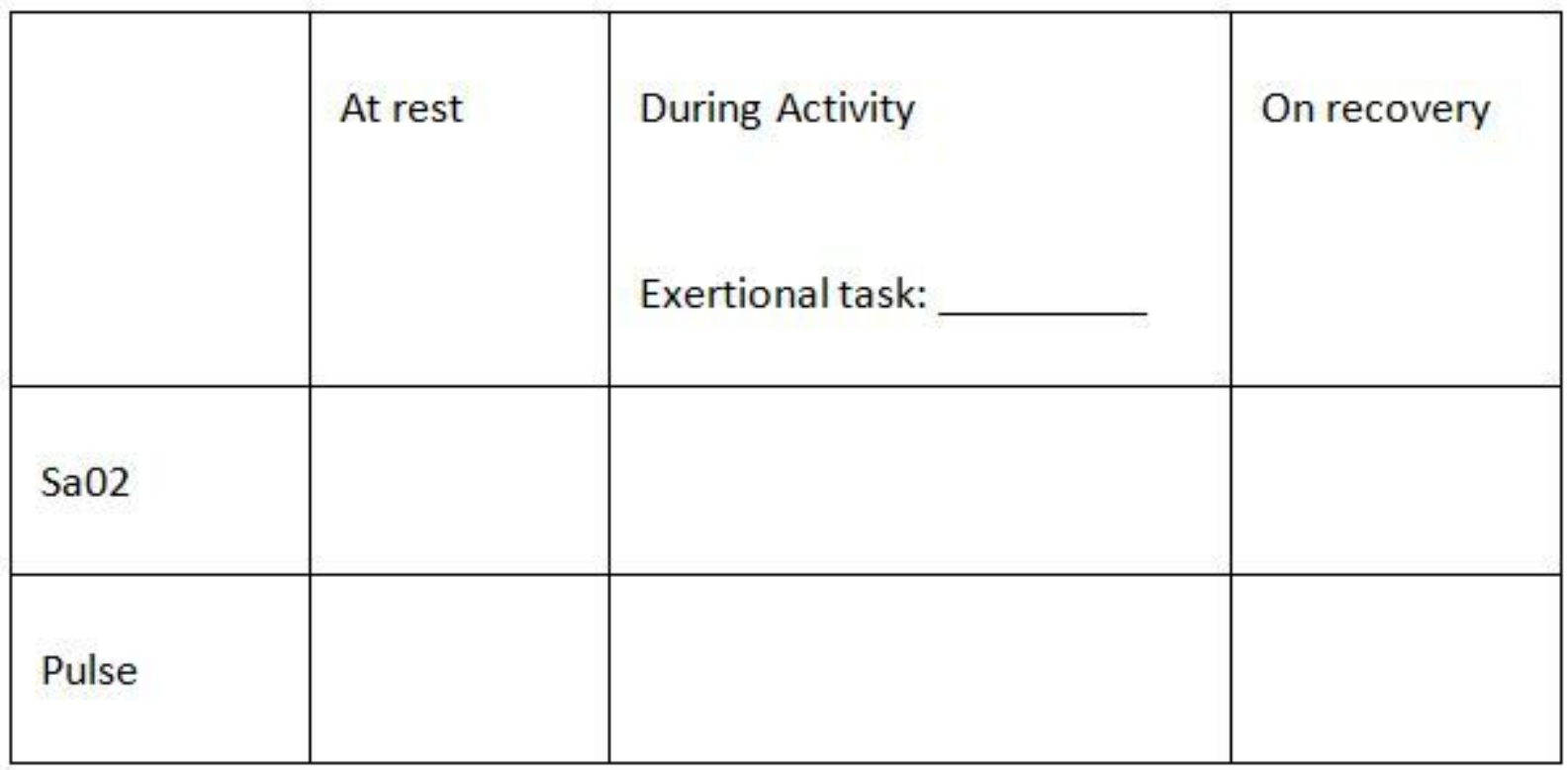

Figure 2

Physiological measurements

Patients self-rate how the dyspnea makes them feel.

Note down the emotion e.g. frustrated, anxious, worried and frightened:

(On a scale of $0-10$, with 0 no at all and 10 being the worst imaginable)

Emotion

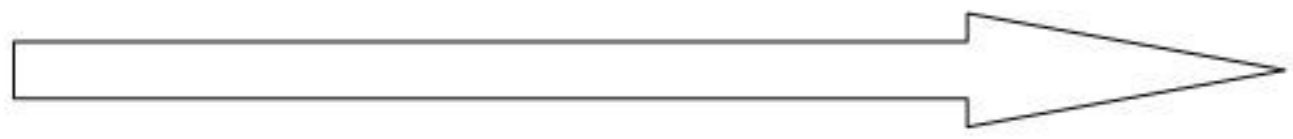

$\begin{array}{lllllllllllll}( & \text { ) } & 0 & 1 & 2 & 3 & 4 & 5 & 6 & 7 & 8 & 9 & 10\end{array}$

Figure 3

Emotion score 
Patients self-rate how confident they are in managing their breathlessness.

(On a scale of $0-10$, with 0 extremely confident and 10 being not confident

at all)

Confidence

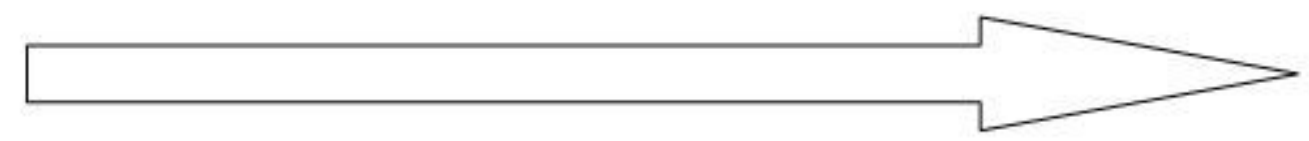

$\begin{array}{lllllllllll}0 & 1 & 2 & 3 & 4 & 5 & 6 & 7 & 8 & 9 & 10\end{array}$

Figure 4

Confidence score 


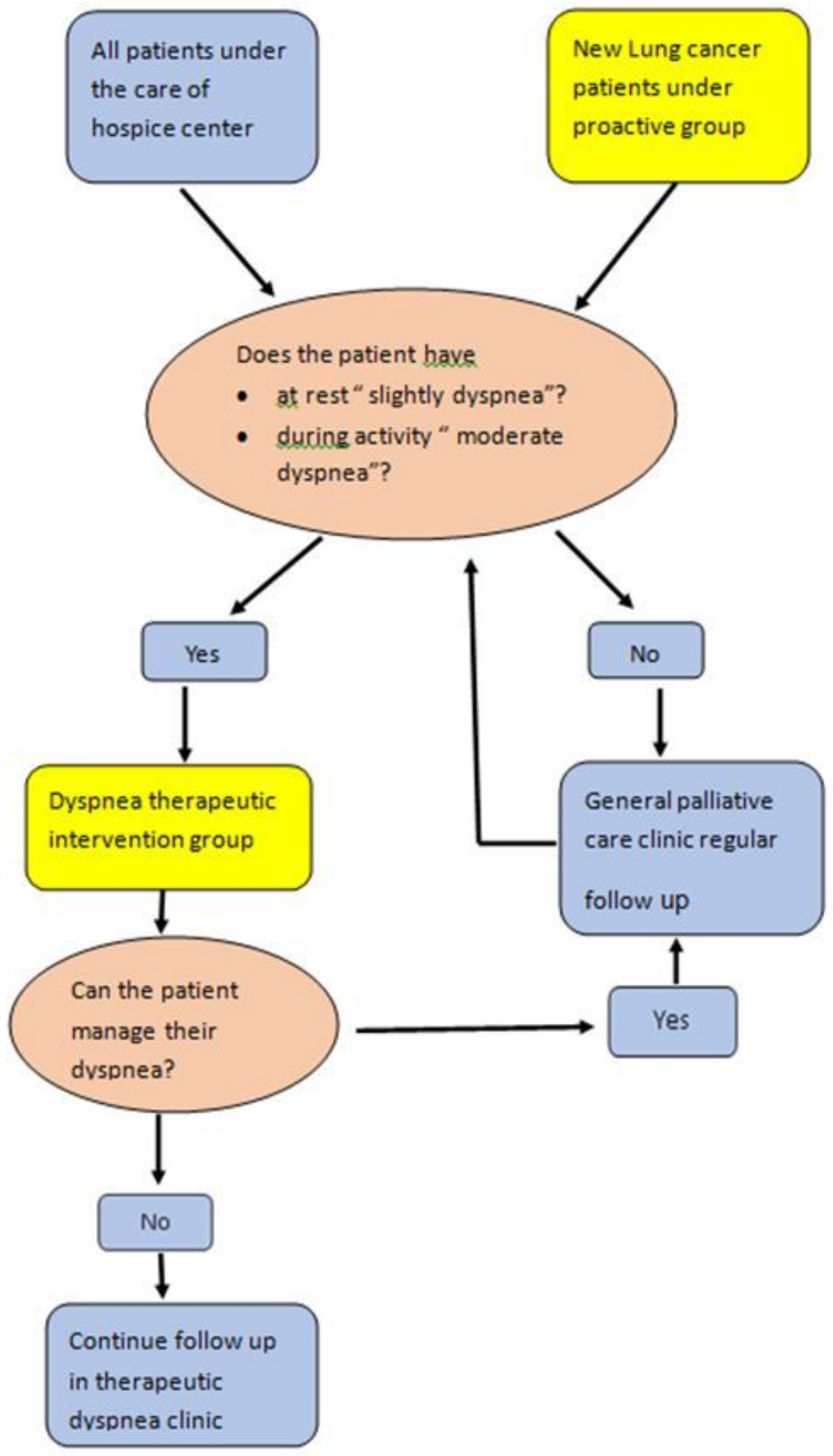

\section{Figure 5}

Flowchart of patient's journey 


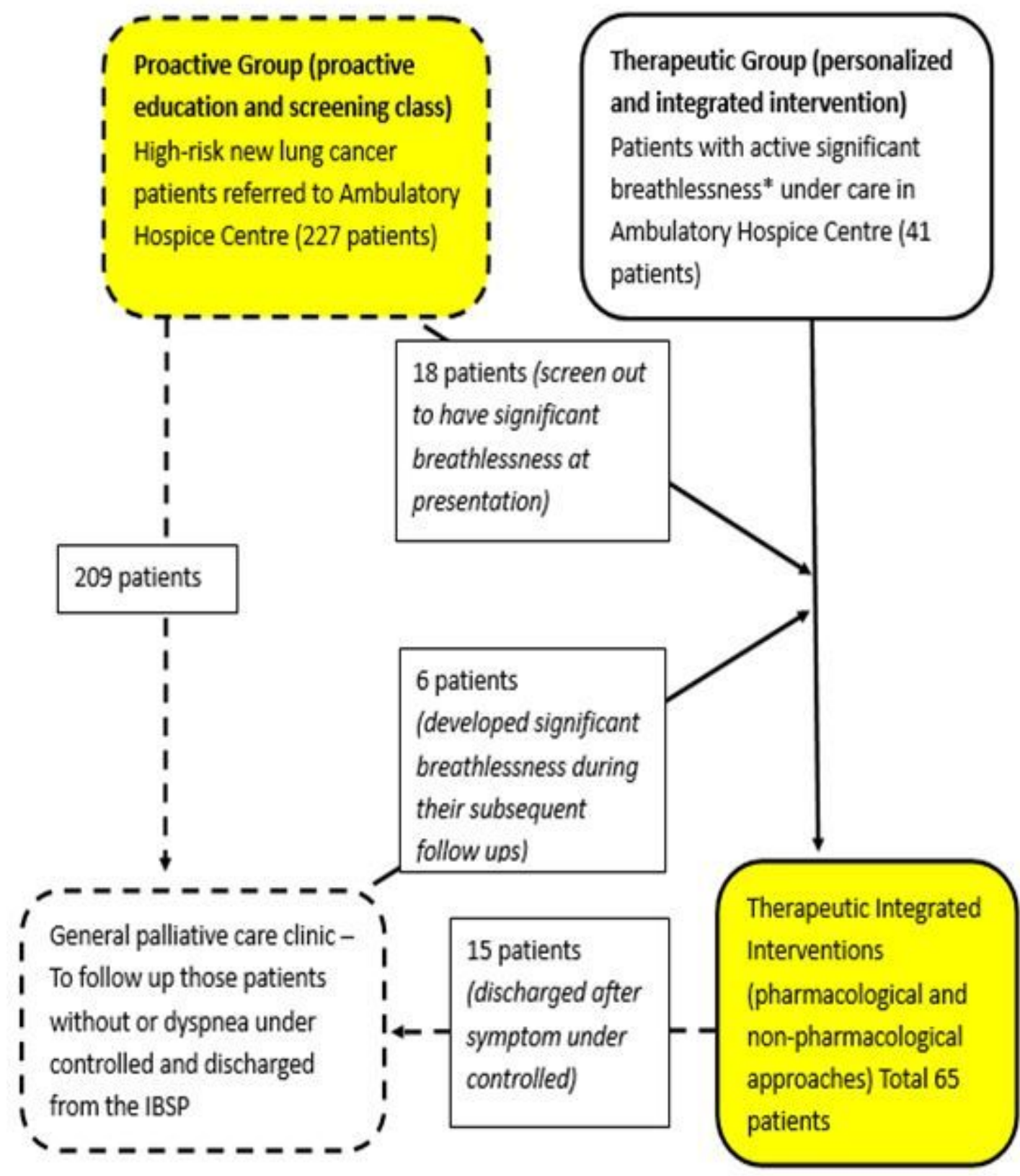

*significant breathlessness is defined as Modified BORG dyspnea score $\geqq$ slight (2 $/ 10)$ at rest and/or $\geqq$ moderate $(3 / 10)$ during activities

Figure 6 
Fig 7 Cohort Outcome of the Proactive Group

All proactive group patients followed up in the palliative care clinic along their whole disease course.

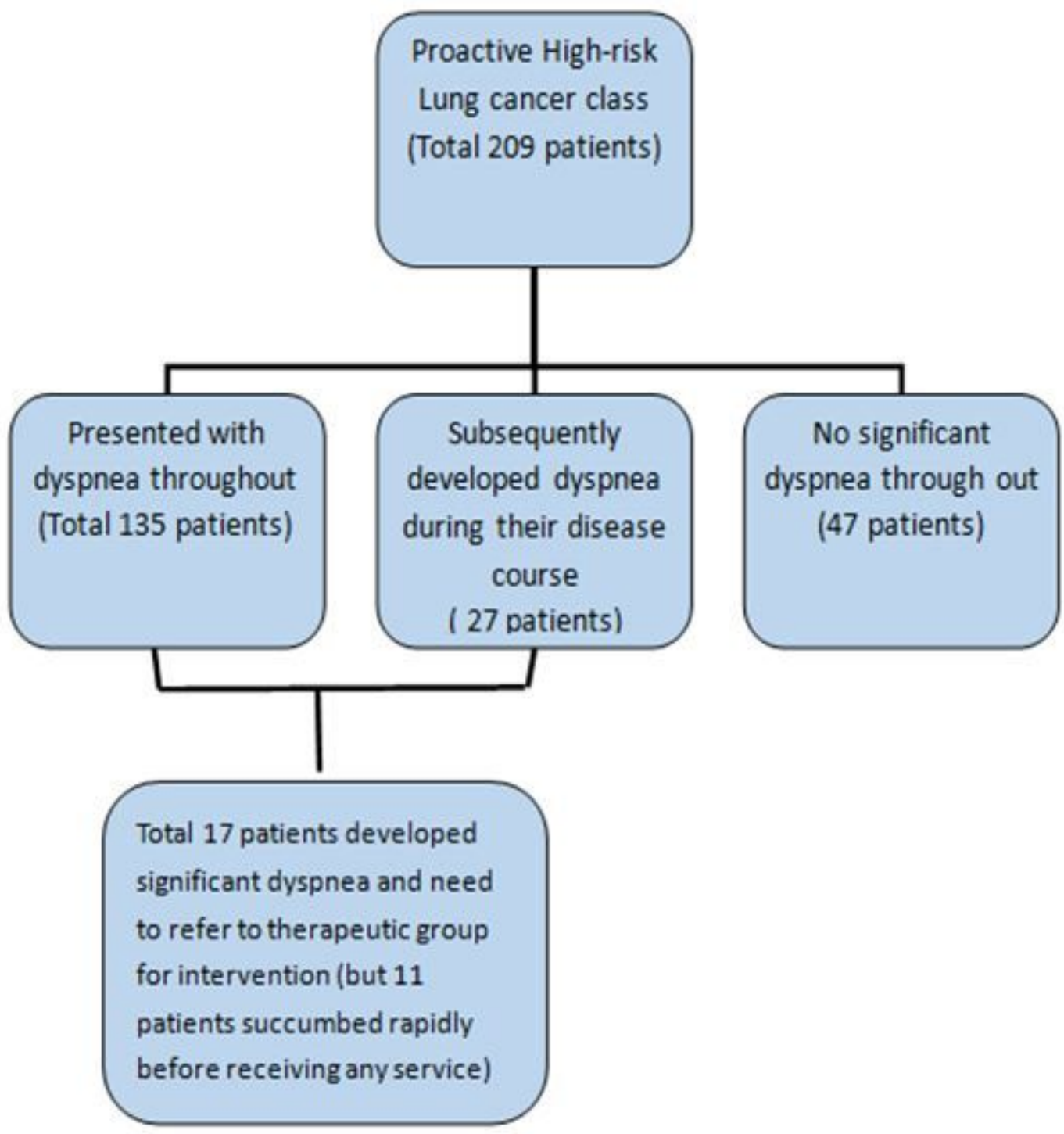

Figure 7

Cohort Outcome of the Proactive Group All proactive group patients followed up in the palliative care clinic along their whole disease course. 


\section{Frequency of emergency department attendance}
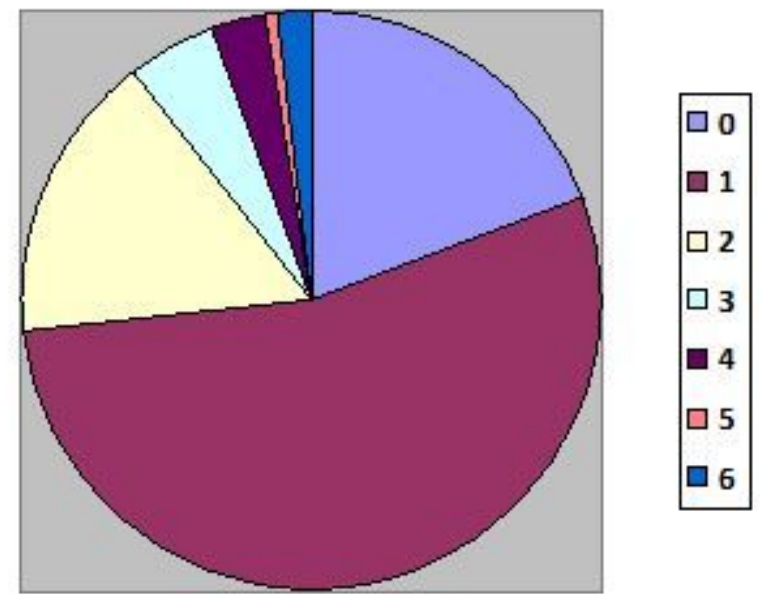

Frequency of unplanned admission

\section{Median Survival: 149 days}

$(1 \sim 1186)$

1 year survival: $22 \%$

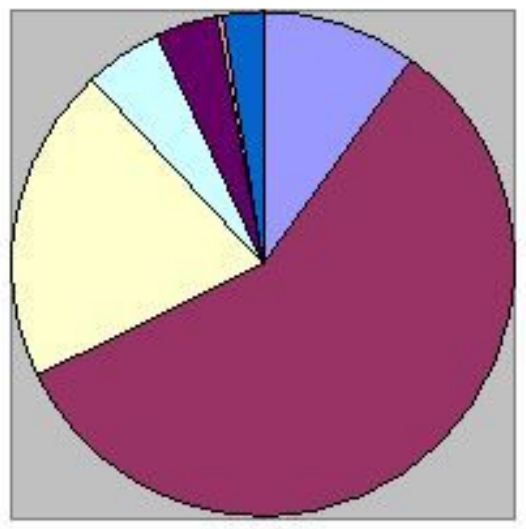

\begin{tabular}{|l|}
\hline$\square 0$ \\
$\square 1$ \\
$\square 2$ \\
$\square 3$ \\
$\square 4$ \\
$\square 5$ \\
$\square / /=6$ \\
\hline
\end{tabular}

Figure 8

Outcome of symptomatic proactive class (162 patients) 
Number of attendances per patient in

the therapeutic group

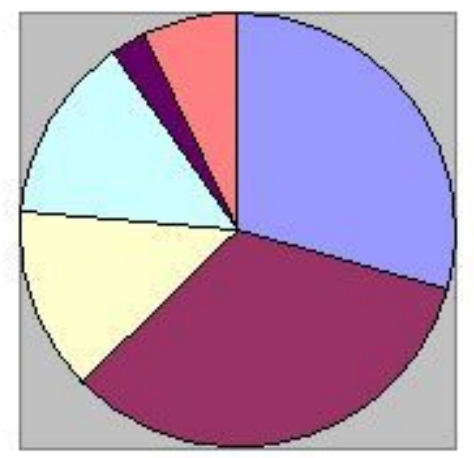

\begin{tabular}{|l|}
\hline$\square 1$ \\
$\square 2$ \\
$\square 3$ \\
$\square 4$ \\
$\square 5$ \\
$\square>/=6$ \\
\hline
\end{tabular}

Figure 9

Therapeutic group: 159 attendances for a total of 65 patients 


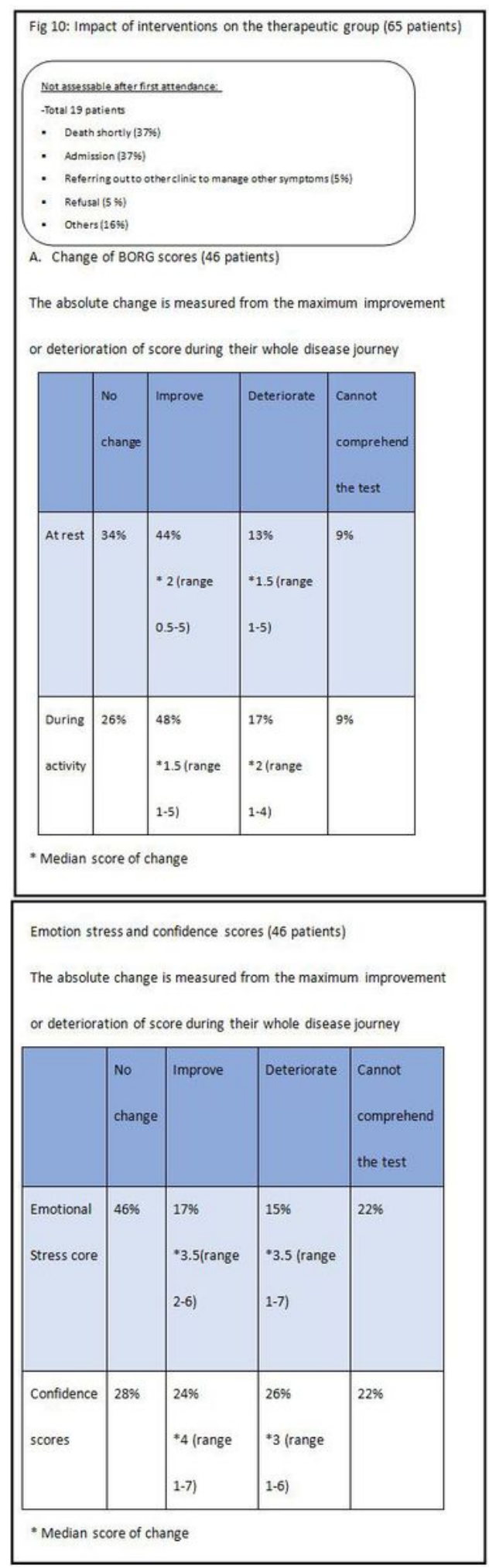

Figure 10

Impact of interventions on the therapeutic group (65 patients) 
Outcome of dyspnea patients on the therapeutic group

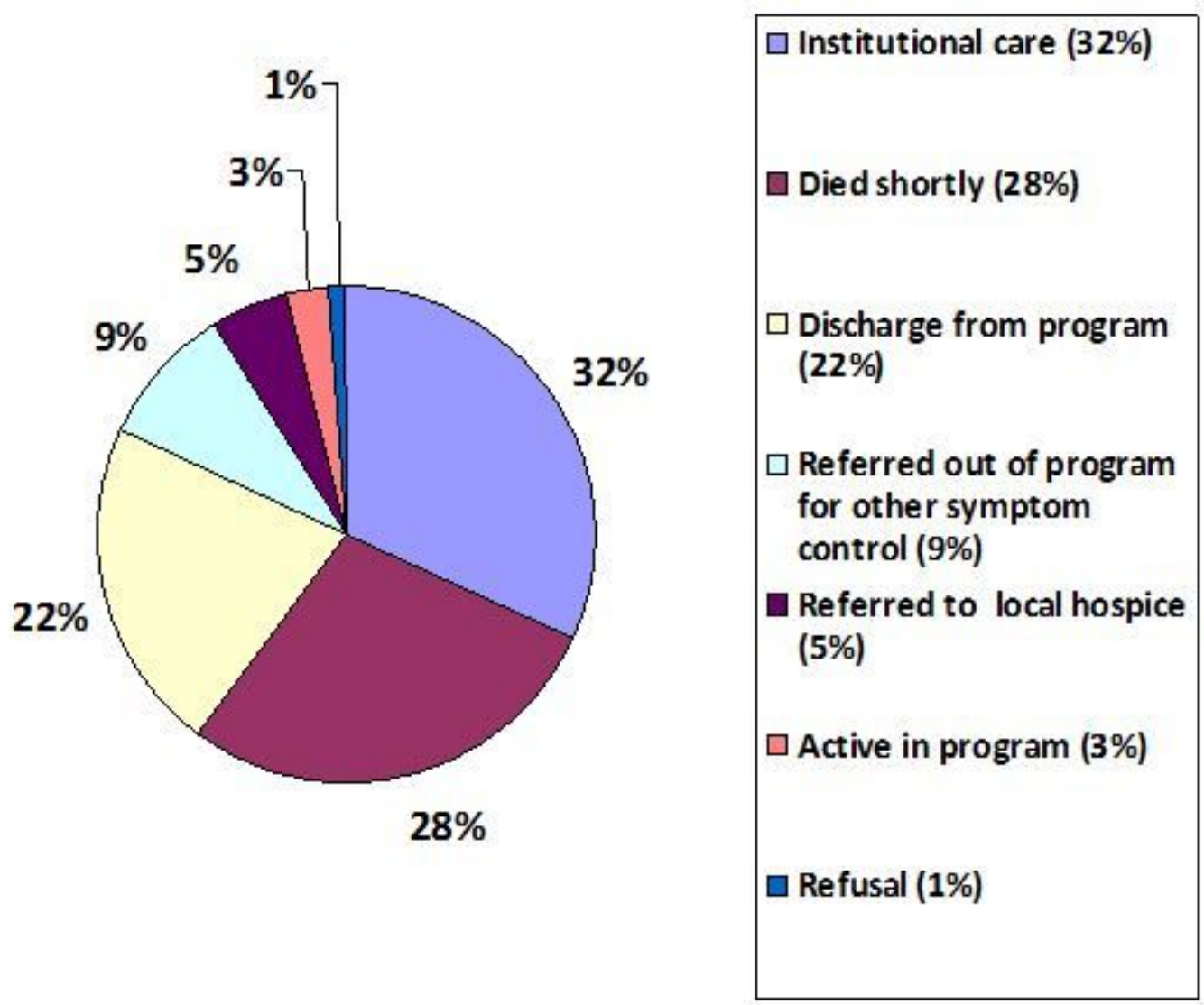

Figure 11

Outcome of dyspnea patients on the therapeutic group 